\title{
Are Immigrants More Likely to Be Involved in Criminal Activity in Saudi Arabia?
}

\author{
Mofza Algahtany ${ }^{1,2}$, Lalit Kumar', Hassan Khormi ${ }^{3}$ \\ ${ }^{1}$ School of Environment and Rural Science, University of New England, Armidale, Australia \\ ${ }^{2}$ Ministry of Justice, Riyadh, Saudi Arabia \\ ${ }^{3}$ Department of Social Sciences-Arts, Jazan University, Jazan, Saudi Arabia \\ Email:malgahta@une.edu.au,.lkumar@une.edu.au,hmkhormi@uqu.edu.sa
}

Received 18 February 2016; accepted 21 March 2016; published 24 March 2016

Copyright (C) 2016 by authors and Scientific Research Publishing Inc.

This work is licensed under the Creative Commons Attribution International License (CC BY). http://creativecommons.org/licenses/by/4.0/

(c) $\underset{\mathrm{EY}}{\mathrm{B}}$ Open Access

\section{Abstract}

This paper aims to explain the effects of immigration on the overall crime rate and in the six most significant categories of crime in Saudi Arabia, being drugs activity, theft, murder, assault, alcohol and outrageous issues, during a ten-year period from 2003 to 2012, in all thirteen administrative provinces, as well as establish the provinces most affected by criminal activities of immigrants during this period. In our finding, no positive association between immigrants and criminal cases was noted. It is clearly visible that the highest rate of overall criminal activities is in the south, north and Makkah areas, where there is high probability of illegal immigrants, supporting the basic criminological theory that areas with high levels of immigrants also experience high rates of crime. The study provides suggestions to the Saudi government, policy and decision makers, and immigration authorities, which could assist in reducing crimes perpetrated by immigrants.

\section{Keywords}

Immigration, Crime, Criminology, Saudi Arabia

\section{Introduction}

Communities worldwide suffer the effects of crime and the deterrence of crime has become one of the most important global tasks, along with the concern for public security [1]. How immigration affects and increases the crime rates has historically been an important consideration in criminological theory and is a major concern of political and public discourse and debate on immigration policy [2]. Immigration and crime are not only a current issue in politics but among the general public. While the juxtaposition of "immigration" and "crime" in the news may create the perception of a causal link, a direct link is presumed to exist [3]. Newton and Felson found 
that the daily visitors have a noteworthy effect on crime rate over the city especially in violent and property crimes [4]. However, Farrell has conducted five tests for a theory of the crime drop. He found that immigrants commit less crime than other, and crime fell while immigration rose [5].

Immigration is an important aspect of crime which has been studied by researchers and criminologists over the last decades, and has led to public concerns regarding immigration where crime levels are high. The relationship between immigration and crime is considered an important theme in criminological research and has led to controversies among scholars [6].

The concern about the tendency of immigrants to become involved in criminal activity is almost as old as immigration itself. Abbott and Van Vechten [7] [8] reported many examples of how immigration was regarded as a probable inflow of criminals in the 19th century in the United States. There is a common belief in countries of the Organization for Economic Cooperation and Development (OECD) that immigrants commit more crimes than natives [9], thereby causing an overall increase in crime levels. On the other hand, some studies of migrants' criminality found that immigrants are less likely to commit crime than native [10]. It is generally conceded that lower class groups suffer greater social disorganization and the associated factors of anomy and environmental change with higher rates of crime, which emphasizes why migrant groups exhibit higher rates of crime than non-migrants [11].

A sociologically-oriented criminology emerged in the twentieth century in the US, investigating the migratory processes of Southern and Eastern European peasants to the Americas during the great immigration to the North American working class in the first decades of the last century [12]. Certain areas were so prevalent that they became the most important areas of investigations for American sociologists [13]. Robert Park (1928) and Stonequist (1937) saw migrations not by accident or deviance, as part and parcel of the development that characterized the North American politics at the time. The history of immigration movements that produced development, at the same time brought imbalance, crisis and produced the ambiguous condition of the "marginal man”, fraught with possibilities but also with both anomie and pain [14] [15].

Butcher and Piehl (1998) [3] investigated the relationship between immigration and crime in a metropolitan area during the 1980s. They found that cities with high crime rates also had large numbers of immigrants. Further, they pointed to illegal immigration in California where the relationship has received most attention in terms of increased public expenditure on welfare and education. This study also highlighted the area victimization where people in California suffered personal injury and damage caused by the criminal actions of illegal aliens [16]. This seems to provide a strong indicator that illegal immigrants do contribute disproportionately to the rate of crime.

Killias [17] found that, in Switzerland, the proportion of non-Swiss criminal offenders increased during the period from 1982 to 1992. He found the proportion of criminal acts of illegal aliens was greater than that of legal migrants, particularly in the area of violent crime. He also noted that the immigrants were not disproportionately victimized. Cultural, socioeconomic, and social integration factors may play a role in these differences.

Pinotti [18] saw that there were ambiguous implications for immigration enforcement on the crime rate of illegal immigrants. Expulsions reduce the pool of immigrants of committing crimes at risk and also reduce the likelihood of crime for immigrants who are not expelled. He estimated the impact of expulsions on crime rate of illegal immigration in Italy and found that stricter enforcement of migration policies reduced the crime rate of illegal immigrants. He concluded that scarcity of economic opportunities in the formal sector increased the crime rate of illegal immigrants.

The views of some sociologists differed from popular perceptions in their findings that immigrant involvement in crime was actually lower than that of the native population. United States Immigration Commission of 1911 had confirmed that the "foreign born" were less criminal than the native [19]. In more recent decades, Bell and his colleagues [20] examined the relationship between immigration and crime in large migration flows which offered an opportunity to carefully appraise whether the populist view that immigration leads to increase crime levels is supported by rigorous evidence. They considered possible crime effects from two waves of immigration that occurred in the United Kingdom at that time. The first wave consisted of late 1990s and early 2000s asylum seekers. The second was the large influx of workers from EU accession countries that took place from early 2004. They found that the first wave led to a small rise in property crime, while the second wave had no such impact. They saw that there was no noted effect on violent crime from either wave. Evidence from their findings of victims suggests that the changes in crime rates during these two waves of immigration could not be 
counted towards crimes against foreigner people. As a result, they suggested that focusing on the limited labour market opportunities of asylum seekers could decrease the effects on crime rates.

Jaitman and Papadopoulos [21] [22] did not find effects or significant link between crime and immigration in their studies although Papadopoulos found that this estimated link differs across the country and ethnic population.

Mariani [9] offers empirical evidence that crime rates are not necessarily higher among immigrants than natives. However, he showed that in many cases rates are higher among second-generations of immigrants than natives. Mariani took into account the fact that some countries are more endogenous and immigrants might have the choice between working officially and engaging in criminal activities. Countries with a more advanced economy may provide alternative statistics in terms of immigrants' crime rates. The main factors are dependent on socioeconomic and institutional differences between countries, their immigration policies and the restrictions of their immigration laws. Webb and his colleagues [23] found that the young immigrants of the past generations of immigrants face a lot of challenges that the western governments need to research. Also, the age at immigration was playing a pivotal role where Beckley found that older migrants are lesser than younger to commit crime [24].

\subsection{Illegal Immigrants}

Most governments impose quotas on the number of foreigners admitted into the country. However, annually varying numbers of undocumented immigrants enter illegally, with more overstaying their temporary visas. Undocumented immigrants represent a high proportion of all immigration into the United States and European countries [25] [26]. Undocumented immigrants usually face poorer legitimate income opportunities because they cannot obtain employment in the formal sector. Most researchers saw that the reduced opportunities lead to a greater chance of engaging in crime. Freedman et al. \& Bohn (2013) and Baker (2014), have provided evidence consistent with this hypothesis. They looked at the changes in crime rates after the Immigration Reform and Control Act of 1986, which granted legal status to over 2.5 million illegal immigrants in the United States [27] [28]. Mastrobuoni \& Pinotti (2014) and Pinotti (2014) reached the same conclusion based on two natural experiments that occurred in Italy in 2006 and 2007. The findings suggested that lesser access to economic opportunities in the official sector increases the crime rate of undocumented immigrants [29] [30]. An important difference between legal and illegal immigrants is that the latter group face arrest and expulsion by the police and immigration authorities. Pinotti (2015) found that the crime rate of illegal immigrants is typically far higher than that of legal immigrants, and tougher deportation policies were likely to reduce predicted crime rates [18]. However, many would-be immigrants favour illegal immigration if they cannot enter legally into the desired country, with a selection policy unlikely to favour them.

\subsection{Immigration in Saudi Arabia}

Since the late 1960s, vast resources of oil have been discovered in Saudi Arabia, which has been the major factor in the socioeconomic changes in the country. In the 1970s, the impact of these changes became clearly apparent. Cities developed, raising the standard of living through enhancing the economy, creating new jobs, and developing undeveloped regions. However, Saudi Arabia, as a developing country, has lacked a local workforce. For this reason, the government has employed a large number of expatriate labour forces since that time. Economic difficulties of many other Arab and South East Asian countries in the last few decades has made labour emigration to Saudi Arabia an attractive option [31]. Saudi Arabia has become one of the largest markets for Arab and Asian job seekers and remittances from migrant labour back to these countries exceed the value of regional trade in goods and official capital flows [32] [33]. Thus workforce immigration is a major and dynamic economic factor in Saudi Arabia. Although foreigners in Saudi Arabia have not created the problems of the magnitude found in other immigrant regions of the world, Saudi Arabian labour immigration has allowed for rapid economic development, but simultaneously imparted a number of negative cultural and socio-economic consequences [34].

Although, there are some studies in Saudi Arabia that have discussed some aspects of foreign labours issues such as [35] who discussed the role of foreign workers in the promotion of drugs in Riyadh, and [36] who discussed the maids criminal in Saudi society, however, there have been no published studies that have investigated the link between criminal activities and immigration in Saudi Arabia. This paper will be considered as a "groundbreaking" attempt to uncover important information about immigration and crime in all provinces of the 
country, and on such extensive long-term data. In this paper, we will discuss the effect of immigration on overall rates of crime and rates in the six major criminal categories, being drug activity, theft, murder, assault, alcohol and outrageous issues (sex related crime such as adultery and sodomy) in Saudi Arabia for Saudi and non-Saudi people through a ten year period from 2003 to 2012, utilizing separate statistics with annual increases for natives and immigrants, to assess the extent of the immigration effect on the crime rate in Saudi Arabia, to determine the relationship between immigration and crime rate and which region has been most affected by immigration.

\section{Data and Methodology}

\subsection{Study Area}

This study was conducted in Saudi Arabia. It is the largest country in the Arabian Peninsula in terms of area, measuring approximately two million square kilometres [37] and constituting a major part of the Arabian Peninsula. It has a population of approximately 30 million (Central Department of Statistic \& Information of Saudi Arabia, 2013), distributed across 13 administrative provinces.

\subsection{Saudi Government System}

The main punitive policy in Saudi Arabia is controlled by Islamic Law which is based on both determent and penalty, and is described by sureness and quick in implementation, while positive law is used in the western countries as the punitive policy. Positive law is based mainly on offender reformation and the justice, which is considered purposeful and slower than Islamic law [38]. Islamic law (Shari'ah) is the guideline for all legal aspects in Saudi Arabia. Sacred and the secular in the society are the same in the Shari'ah, and therefore in Saudi Arabian law. Shari'ah law has four main ordered sources. The first source is the Holy Qur'an. If the matter has no explanation in the Qur'an, they will review the Sunnah, which is the practice of Prophet Muhammad during his life. If no reference is found any related in Sunnah, the scholars will take the decision which is the third source of Islamic law. "Ijma" is the consensus of decision of Muslim scholars about any matter that happens after the death of Prophet Muhammad and it is not founded in Qur'an or Sunnah. The fourth source in Islamic law is Qias, or analogy. Shari'ah assumes that the defendant is guiltless until certain that he or she is guilty by evidence and substantiation or confession. Qias is used in cases of repeated crimes if there is analogy with other punishment [39].

\subsection{Data Sources}

Two principle sources of data have been used in this study. First, crimes committed by Saudi and non-Saudi for each province from 2003-2012, recorded by the Ministry of Justice on an annual basis, and includes separate statistics regarding criminal issues for Saudi and non-Saudi people, drug activity, theft, murder, assaults, alcohol and outrageous cases (sex related crime) (Ministry of Justice, 2003). This data collection spans ten years from 2003 to 2012. It should be noted that this criminal data is based on cases that have been finalized judicially, by instrument or decision, which gives it a high accuracy. Second, population counts for Saudi and non-Saudi for the 13 provinces during this period were obtained from the Central Department of Statistics \& Information of Saudi Arabia.

\subsection{Data Analysis}

With all the accurate data necessary and ready to use for each province, we did not need a complex method. Firstly, the sum of all criminal activates was divided by ten to get the annual average of all of criminal cases through the period and then divided by 1000 to give the rate of overall crime per 1000 people per year. This approach gave an overview of overall criminal activity in Saudi Arabia. Secondly, we calculated the rate of each crime for each province through this period (2003 to 2012) per 1000 people for Saudis and non-Saudis for comparative purposes. We then used a classification technique in ArcGIS software to find the average of overall crimes in Saudi Arabia throughout this period and which provinces were more affected. To see the ratio of Saudi and non-Saudi, we divided the population into the two groups and performed the same operation for both (Figure 1), to explain the spatial distribution of overall criminal activities in the whole country, where the darker 


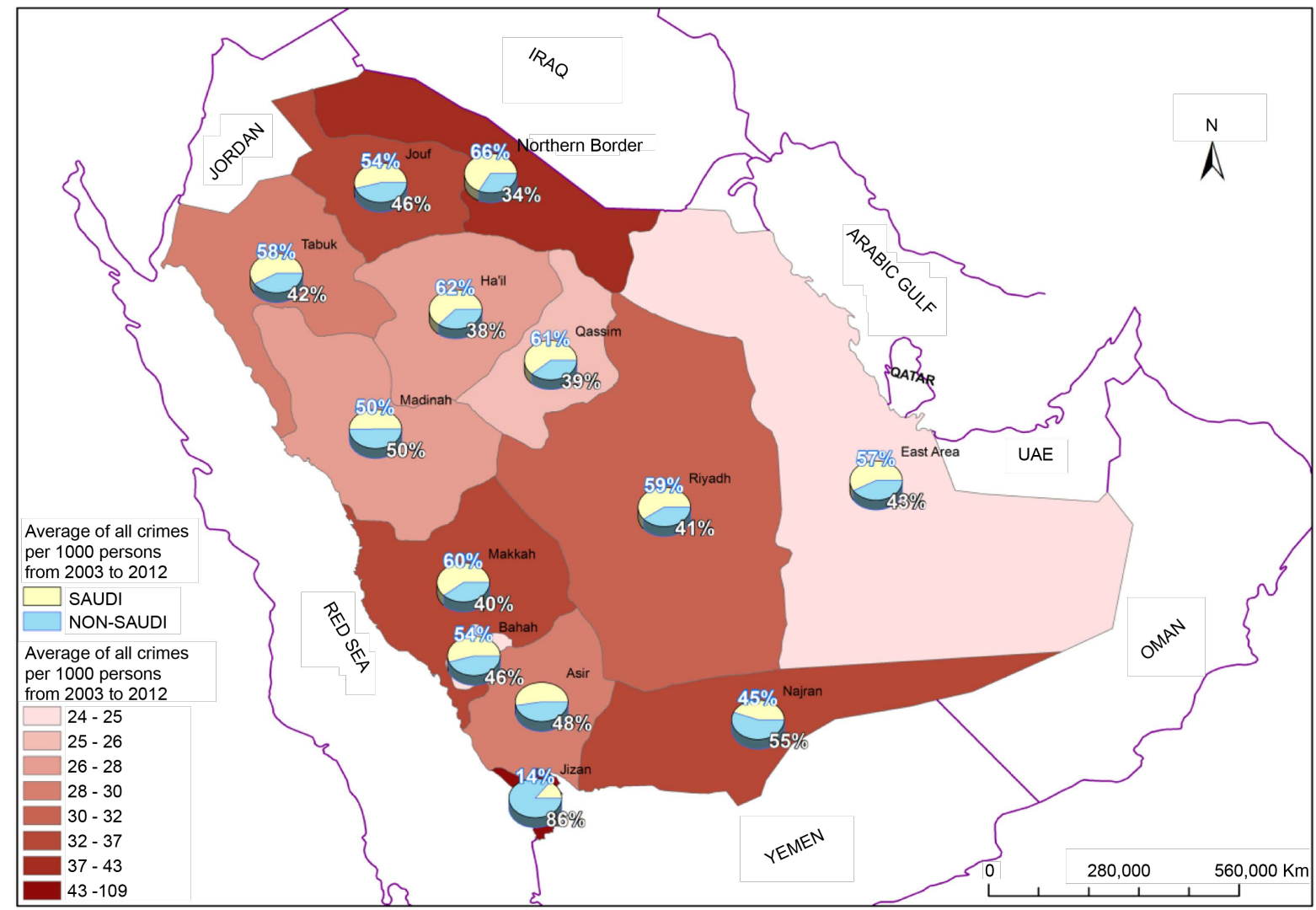

Figure 1. Spatial distribution of overall criminal activities and the ratio of Saudi and non-Saudi criminal activities. The yellow portion shows the ratio of overall Saudi criminal activities while the blue portion shows the overall criminal activities for non-Saudi people.

colour represents the highest rate of crime and the lighter colour represents the lowest rate of criminal activities in a specific area. Thereafter we presented the overall criminal activities for the total population, presenting the ratio of Saudi and non-Saudi crimes as pie charts for each province, where the yellow portion represents the ratio of overall Saudi criminal activities while the blue portion represents the overall criminal activities per 1000 people throughout this period for non-Saudi people. To calculate the ratio for each crime for each province for each year, we have used criminal and population data for each province, for Saudi and non-Saudi separately. We calculated every criminal category separately, dividing them by ten, and multiplying by 1000 to give crimes per 1000 persons annually. The same process was applied for each province for Saudi and non-Saudi population for each year and for each crime separately and the trend computed by line graph (Figures 2-14).

\section{Results}

The provinces with the highest crime rates, as shown in Figure 1, are Jizan, Northern Border, Najran, Makkah and Jouf, while Baha, Qassim and East Area display the lowest rates. The highest proportion of non-Saudi crime was in Jazan with 86\%, followed by Najran with 55\%, and Madinah with around 50\%. Jouf, Bahah and Asir were about 47\%. The ratio in the remaining provinces Riyadh, East Area, Makkah, QassimHa'il and Tabouk were similar, around $40 \%$. This is an overview of the overall crime rate for Saudi and non-Saudi people throughout the ten year period from 2003 to 2012 per 1000 persons annually.

\subsection{Provinces}

Having provided an overview of overall criminal activities for both the Saudi and non-Saudi populations throughout the ten years, we then calculated the ratio for both Saudi and non-Saudi during this period, for each crime category and for each province separately, to get a detailed result for each province and ascertain which 


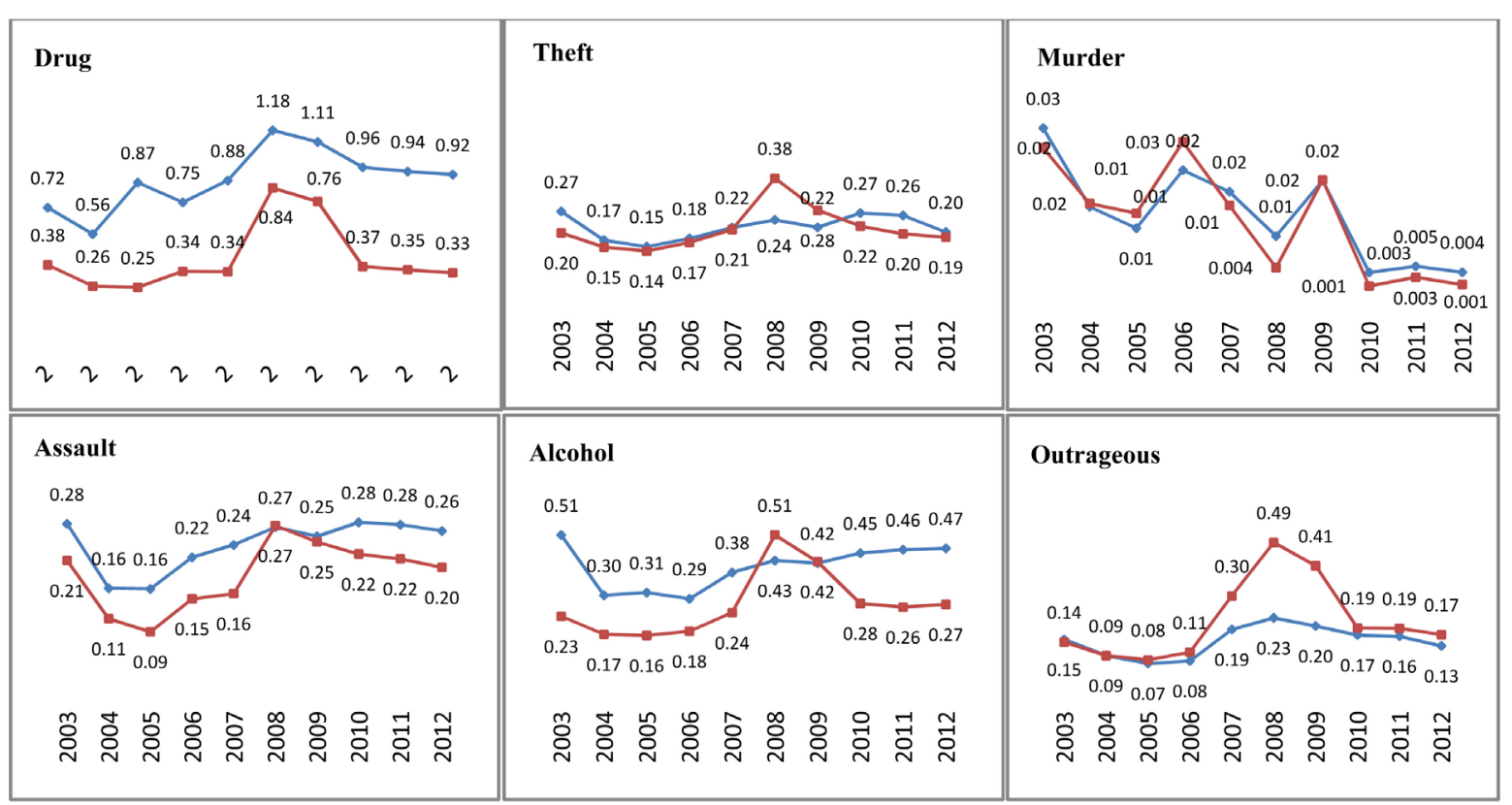

$\because$ SAUDI $\rightarrow$ NON-SAUDI

\section{Figure 2. Criminal activities of Riyadh.}

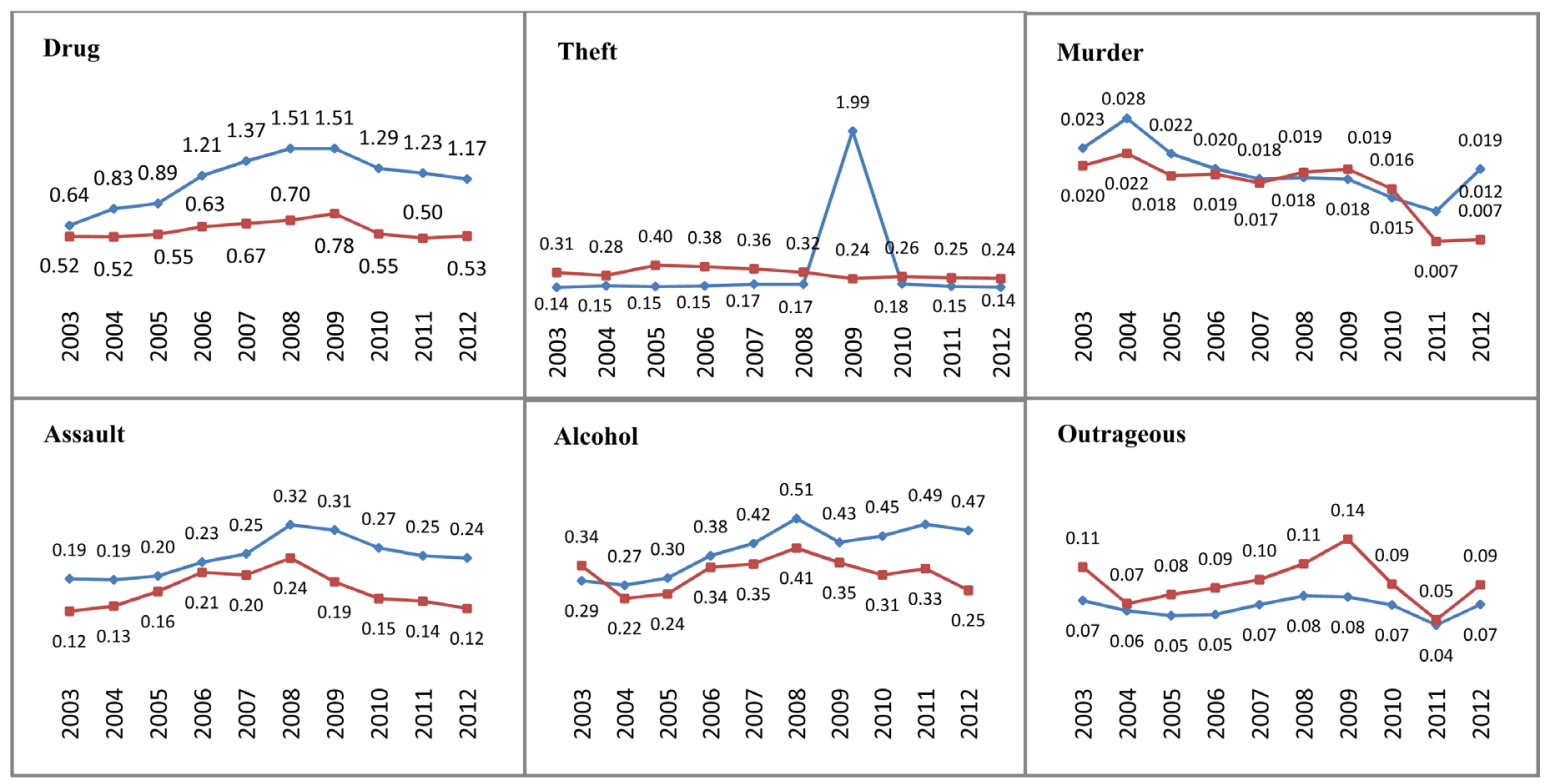

$\because$ SAUDI

Figure 3. Criminal activities of Makkah.

provinces were most affected by immigration, in terms of the variance of population of each individual province.

\subsubsection{Riyadh}

Figure 2 shows the contrast for the six criminal categories between Saudi and non-Saudi in Riyadh, which is the capital city. Saudi people displayed the highest rate of drugs activity. The variance between Saudi and non-Saudi offences was approximately the same during the period with a notable peaking in both lines in 2008 and 2009. Non-Saudi remained lower than Saudi in the theft category with not much difference until the peaks 


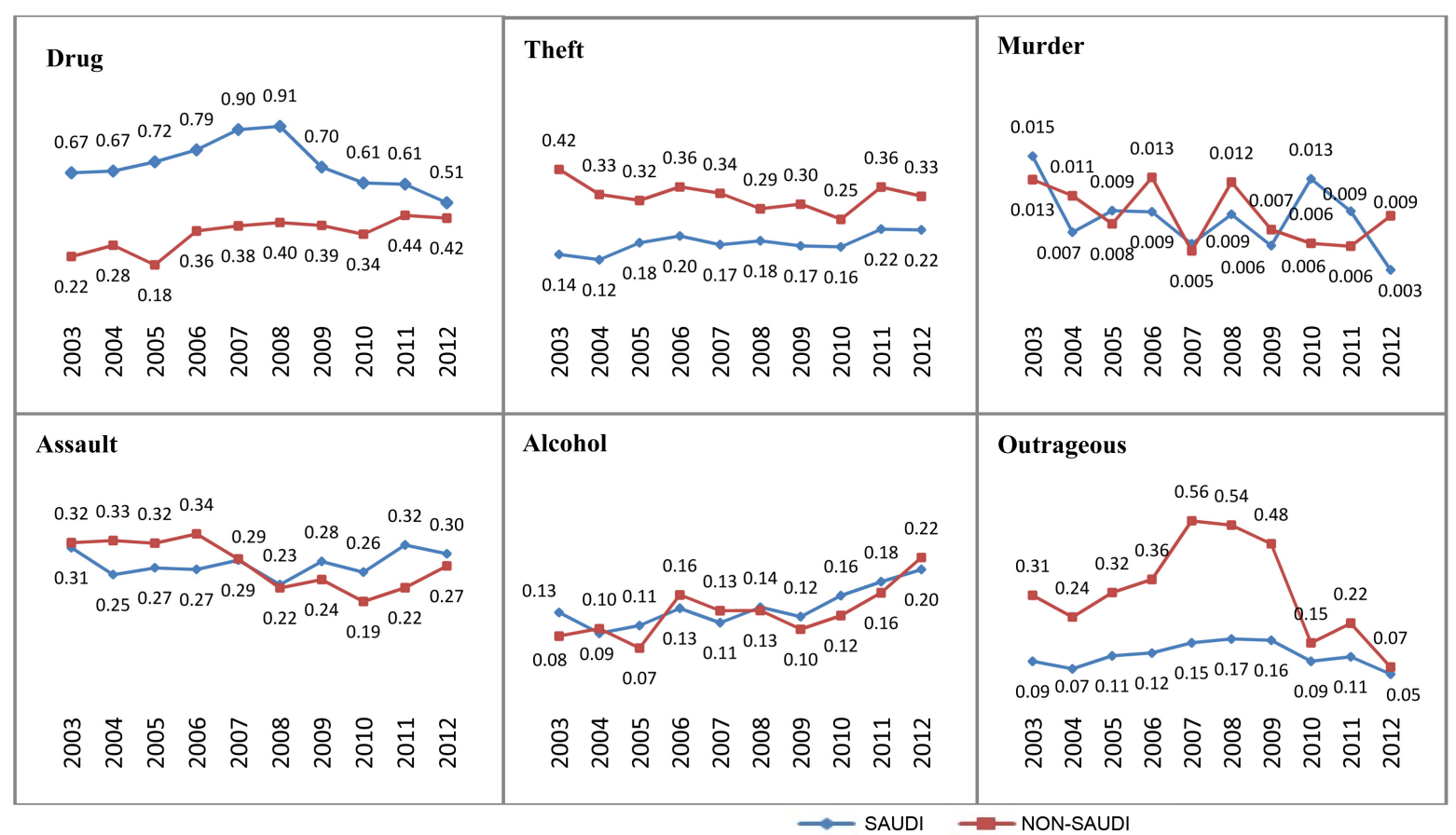

Figure 4. Criminal activities of Madinah.

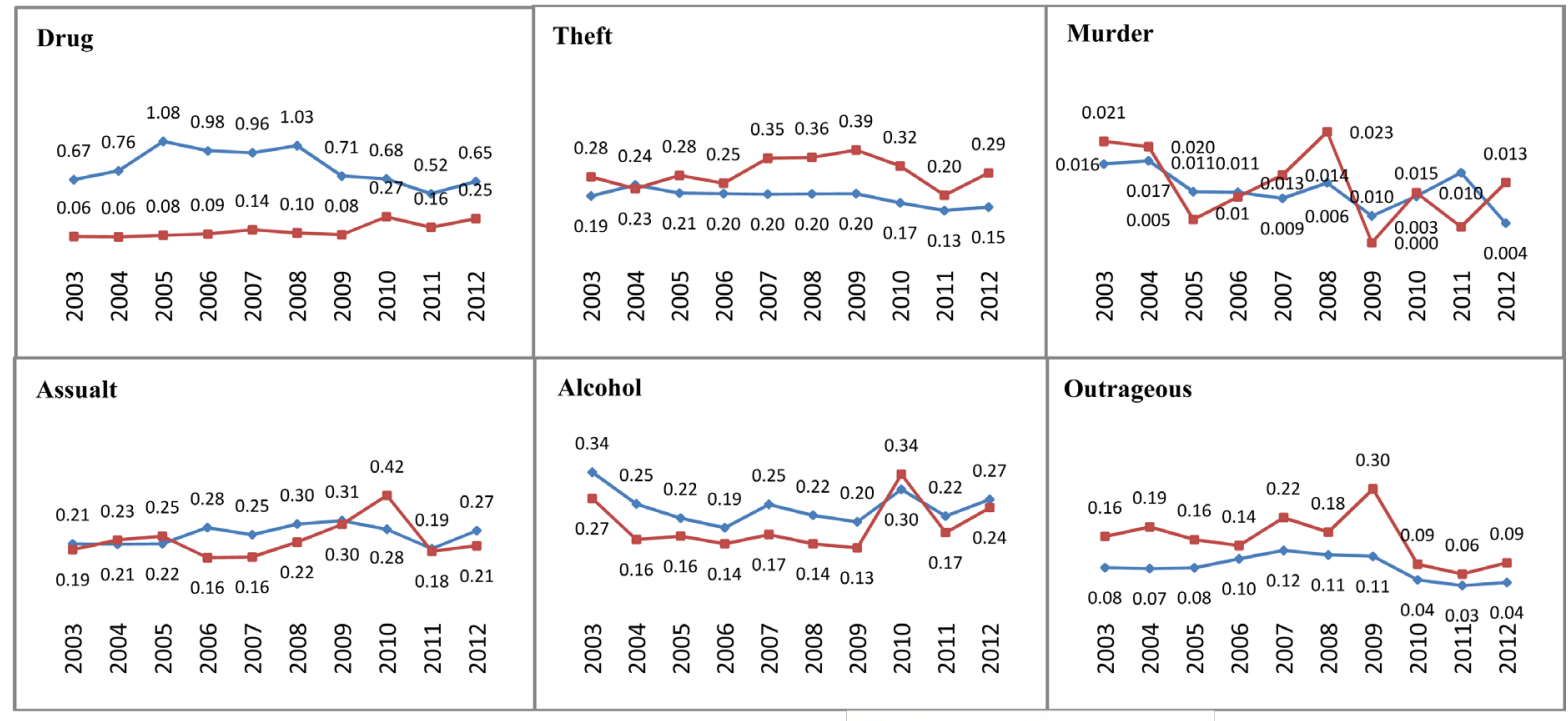

$\because$ SAUDI $\because$ NON-SAUDI

\section{Figure 5. Criminal activities of Qassim.}

in 2008 (variance of 0.14 cases per 1000) and 2009 (0.6 cases per 1000). After that, the trend reverts to being less than Saudi people until the last year of study, where both population types were equal with 0.19 cases per 1000. In 2005 and 2006, the rates of the non-Saudi murder category were higher than Saudi, but equal in 2004 and 2009. Over the last three years of the study period, non-Saudi rates are again less. There was a rise in non-Saudi assault from 2005 until it equalled Saudi assault in 2008, but thereafter reducing to again be lower than Saudi. Alcohol-related issues for non-Saudis were much lower than for Saudi throughout the period, except where the rate exceeded the Saudi rate in 2008 by more than 0.8 cases per 1000 and was equal in 2009. The most important variance was found in the outrageous category (sex-related crimes) where the variance was greatest with non-Saudi exceeding Saudi from 2005 to the end of 2010. Overall, non-Saudi crimes were less 


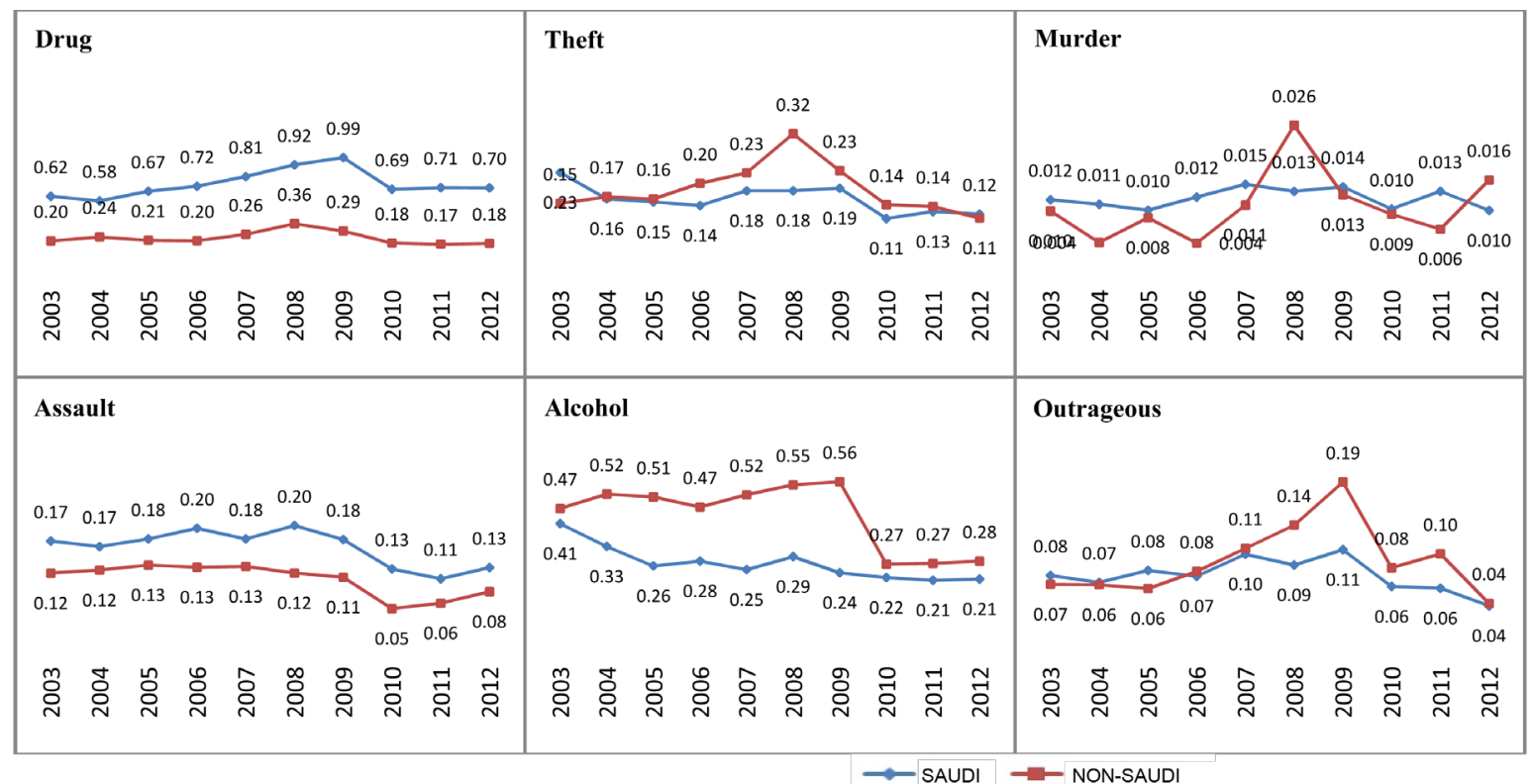

Figure 6. Criminal activities of East Area.

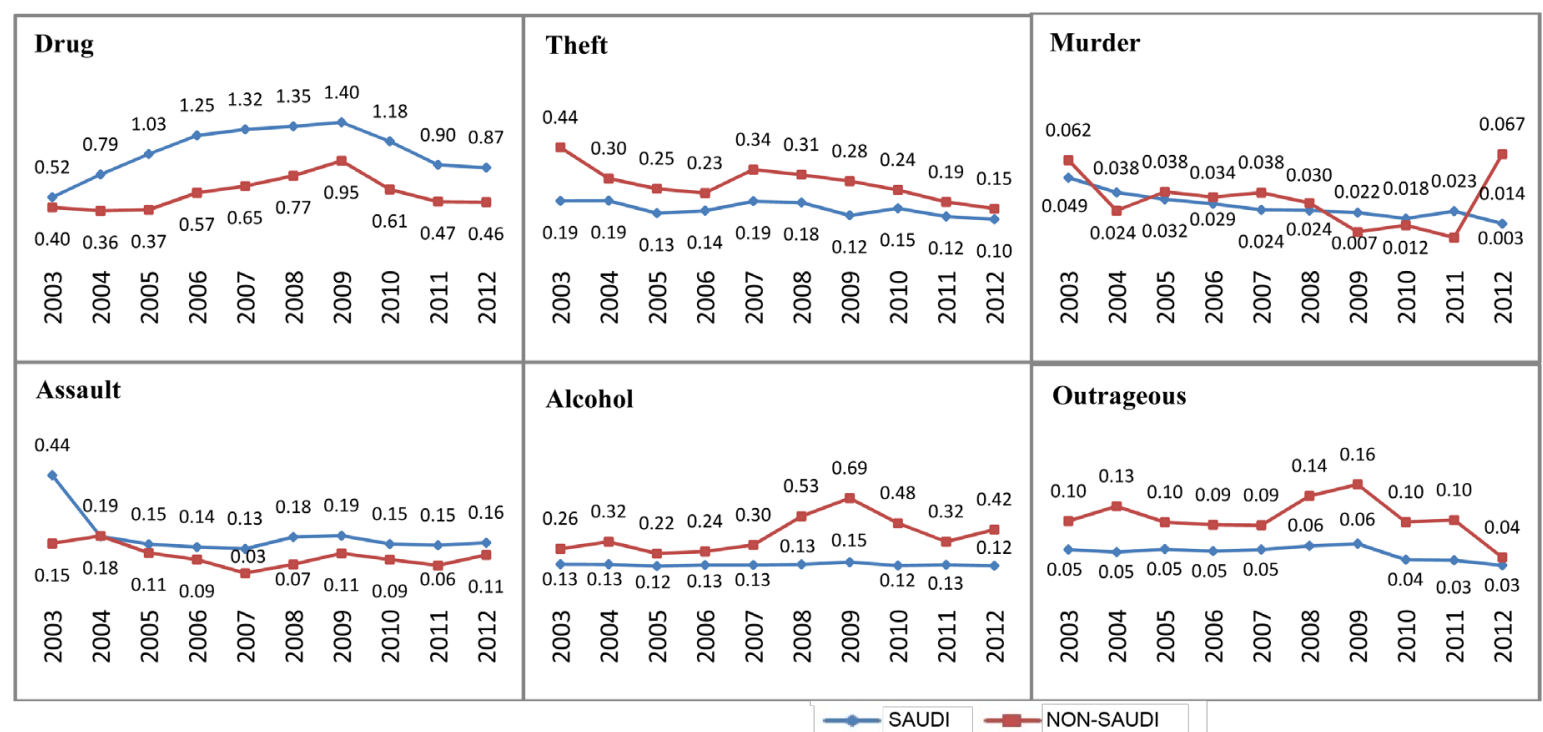

Figure 7. Criminal activities of Asir.

than Saudi crimes.

\subsubsection{Makkah}

In Makkah, the non-Saudi showed the highest rate in theft and outrageous issues during the period except in 2009 where Saudi theft cases peaked with a very high ratio of about 2 cases per 1000 persons. In murder Saudi was high in the first four years, but from 2007 non-Saudi increased to exceed Saudi until the last two years where the rate was less than Saudi for drug, alcohol and assault, non-Saudi remained less than Saudi throughout the period with a large variance in drug activity and fractionally more alcohol cases only in 2003 (Figure 3). Overall, non-Saudi crimes were less than Saudi crimes.

\subsubsection{Madinah}

In Madinah, non-Saudi rates generally exceeded Saudi throughout this period with a notable variance in the theft 


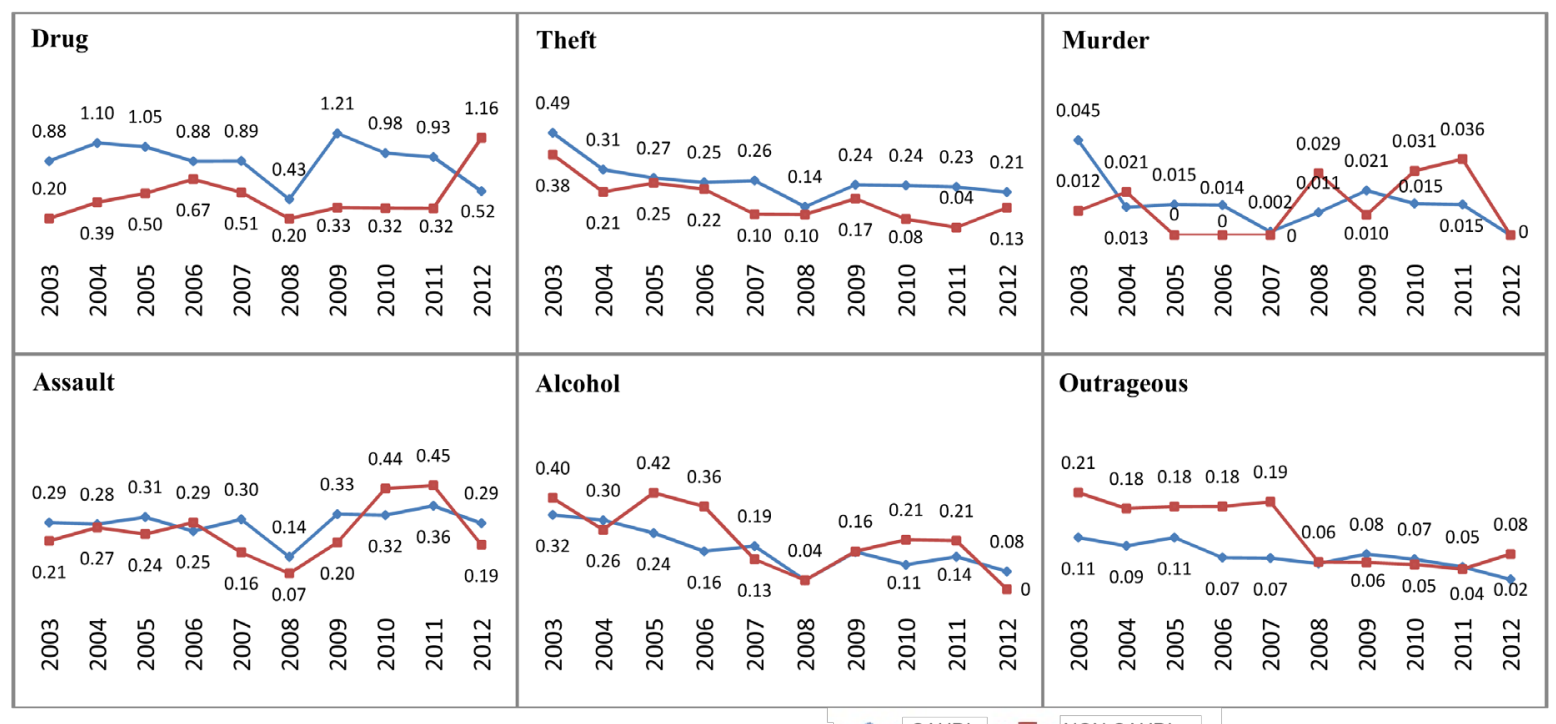

Figure 8. Criminal activities of Tabouk.

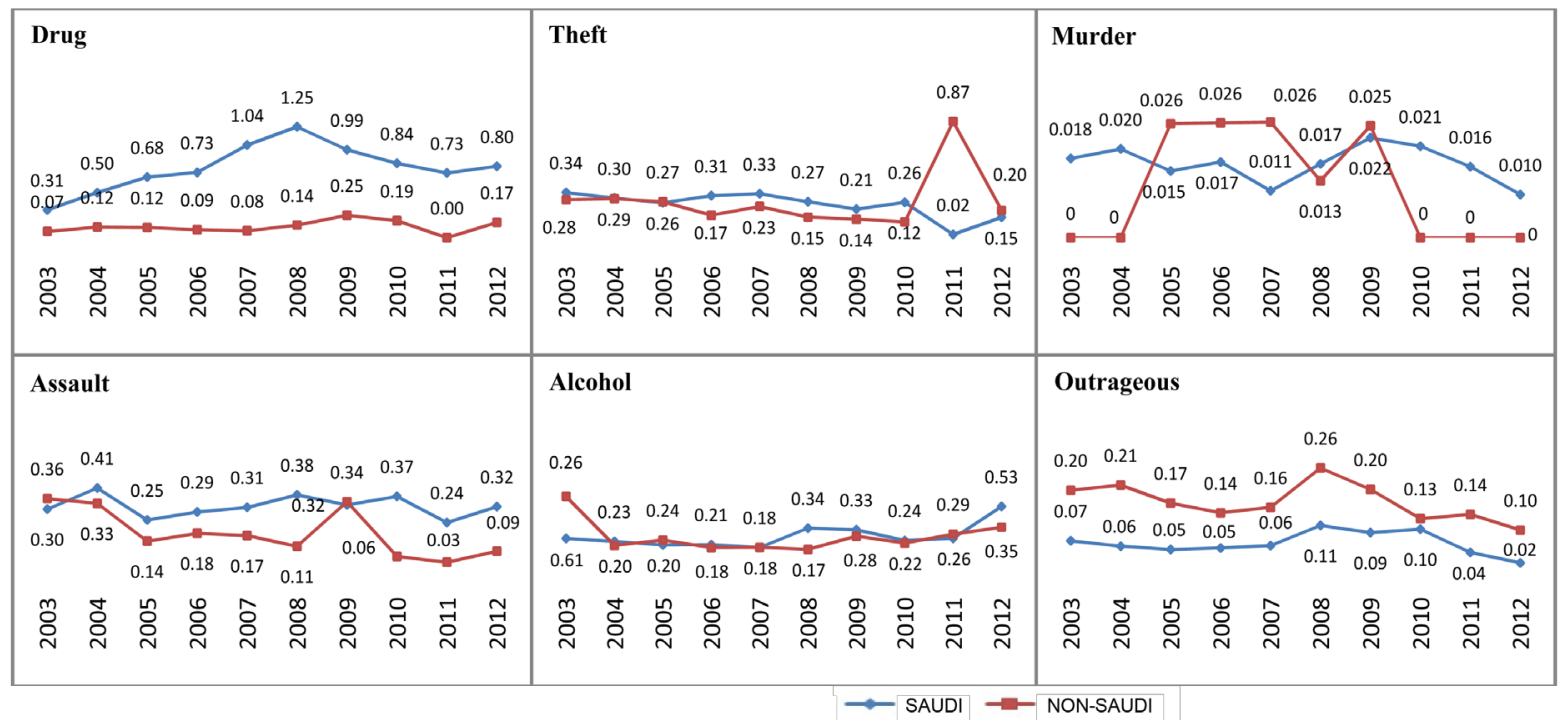

\section{Figure 9. Criminal activities of Ha’el.}

and outrageous categories. From 2004 to 2006, assault exceeded Saudi rates but reduced in the following two years, to remain less than Saudi until the end of 2012. In murder there were notable peaks (2003, 2006 and 2008) for non-Saudi, while similar levels were reached by Saudis in 2003 and 2010. In drug activity, it is noteworthy that the Saudi trend was lower, while non-Saudi were higher, to almost converge in 2012, although the ratio of non-Saudi remained lower than Saudi throughout the period. Both Saudi and non-Saudi rates increased in the alcohol category, after early trend line fluctuations (Figure 4). Overall, non-Saudi crimes were less than Saudi crimes, but not by much.

\subsubsection{Qassim}

In the Qassim area non-Saudis crime exceeded Saudi in the theft and outrageous categories and were higher for six years in murder offences. They exceeded Saudi in 2004, 2005 and 2010 in aggravated assault but only in 2010 for alcohol issue. Saudi exceeded non-Saudi in drug activities throughout the period, although there was a small increase for non-Saudi in the last three years (Figure 5). 


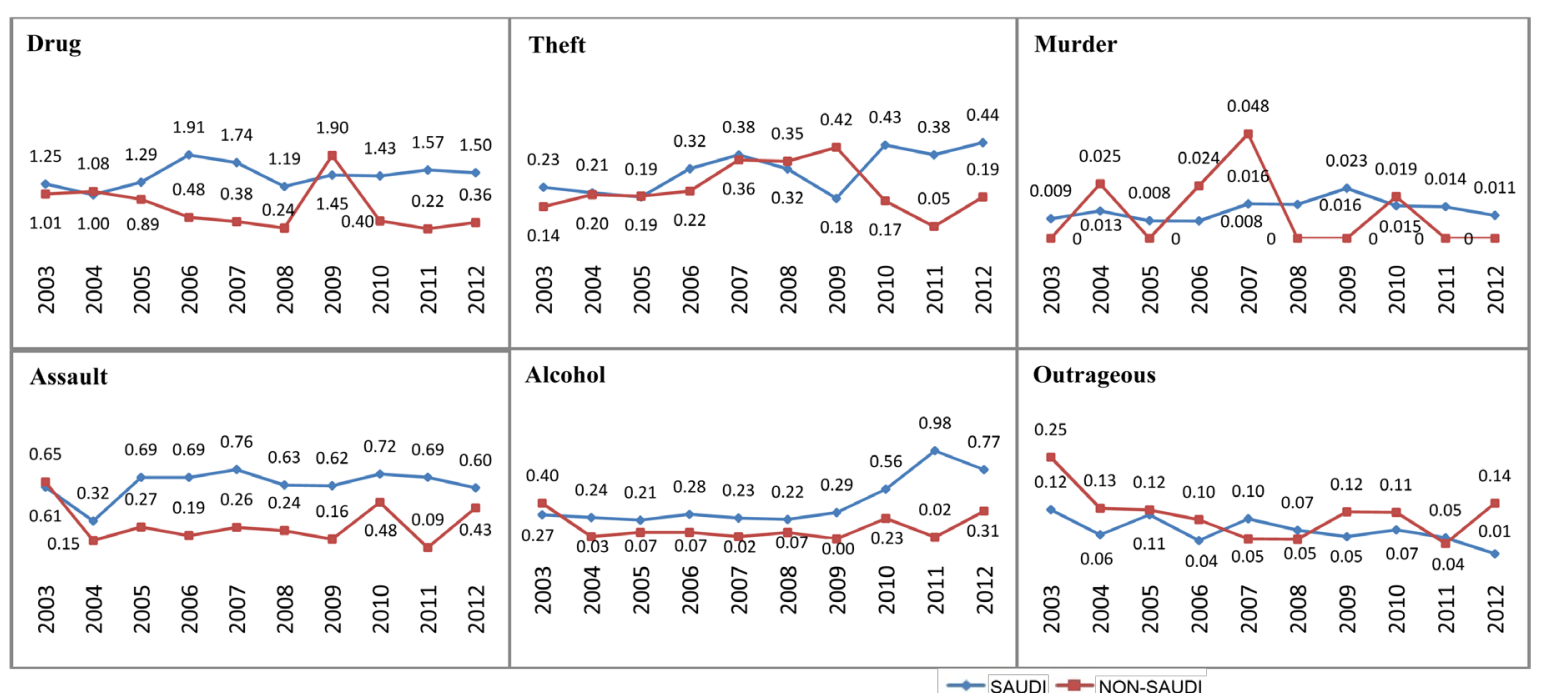

Figure 10. Criminal activities of Northern Borders.

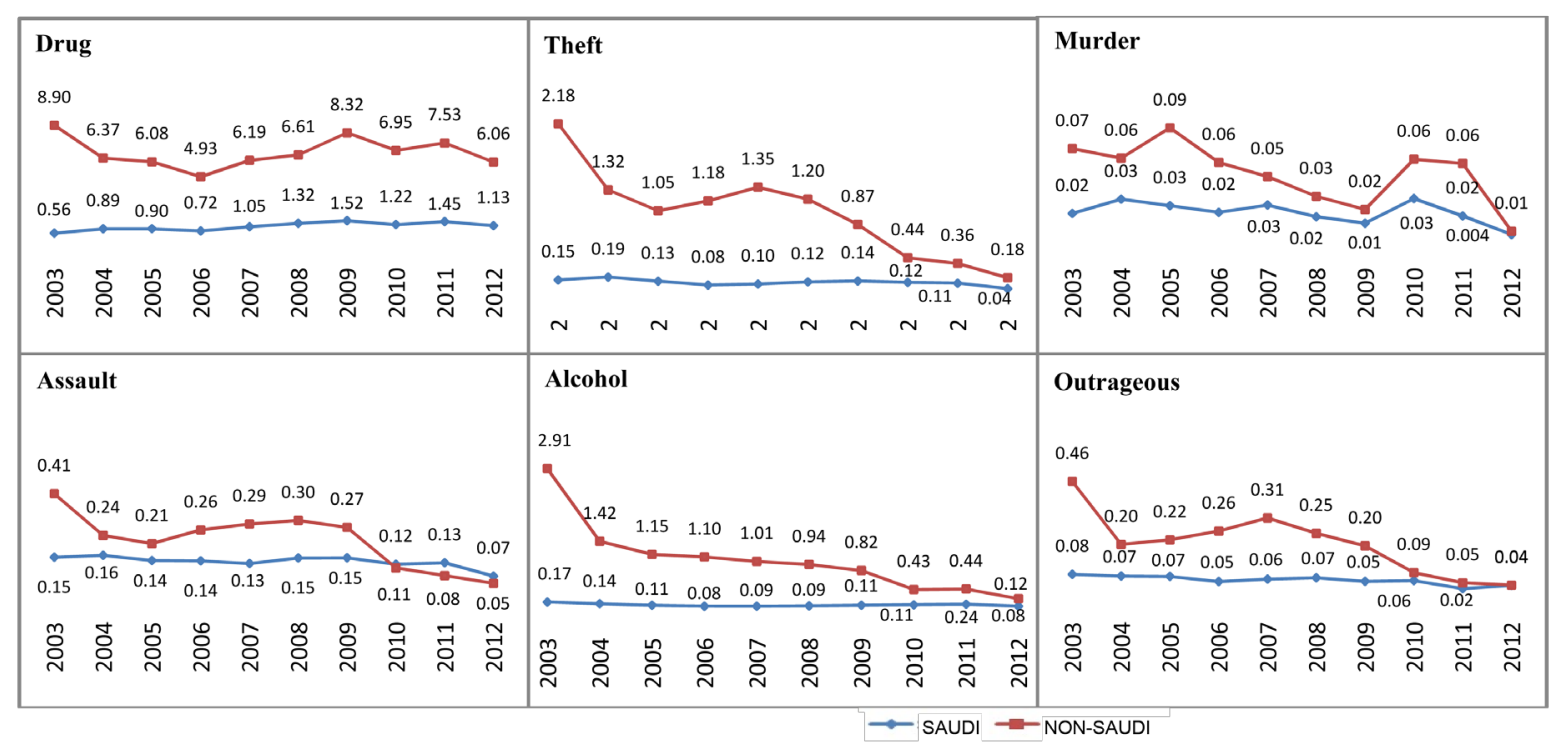

Figure 11. Criminal activities of Jizan.

\subsubsection{East Area}

In East Area non-Saudi exhibited a higher rate in most years in the theft and outrageous categories, and throughout the period in alcohol issues. In drugs and assault Saudis clearly displayed higher rates than non-Saudi. In murder the non-Saudi ratios remained below those of Saudis, except in 2008 when they exceeded Saudis by 0.13 cases per 1000 persons with variance of $50 \%$ (Figure 6).

\subsubsection{Asir}

In Asir, non-Saudis displayed higher rates in theft, drugs and outrageous crimes throughout the period, while Saudis were consistently higher in drug activities. In most years, non-Saudi recorded a higher number of murders including a notable high number in 2012 with a very large variance. In assault non-Saudi remained lower than Saudi except in the first two years of the study period (Figure 7).

\subsubsection{Tabouk}

In Tabouk area, non-Saudi rates were lower than Saudis throughout the period in drug and theft issues except in 


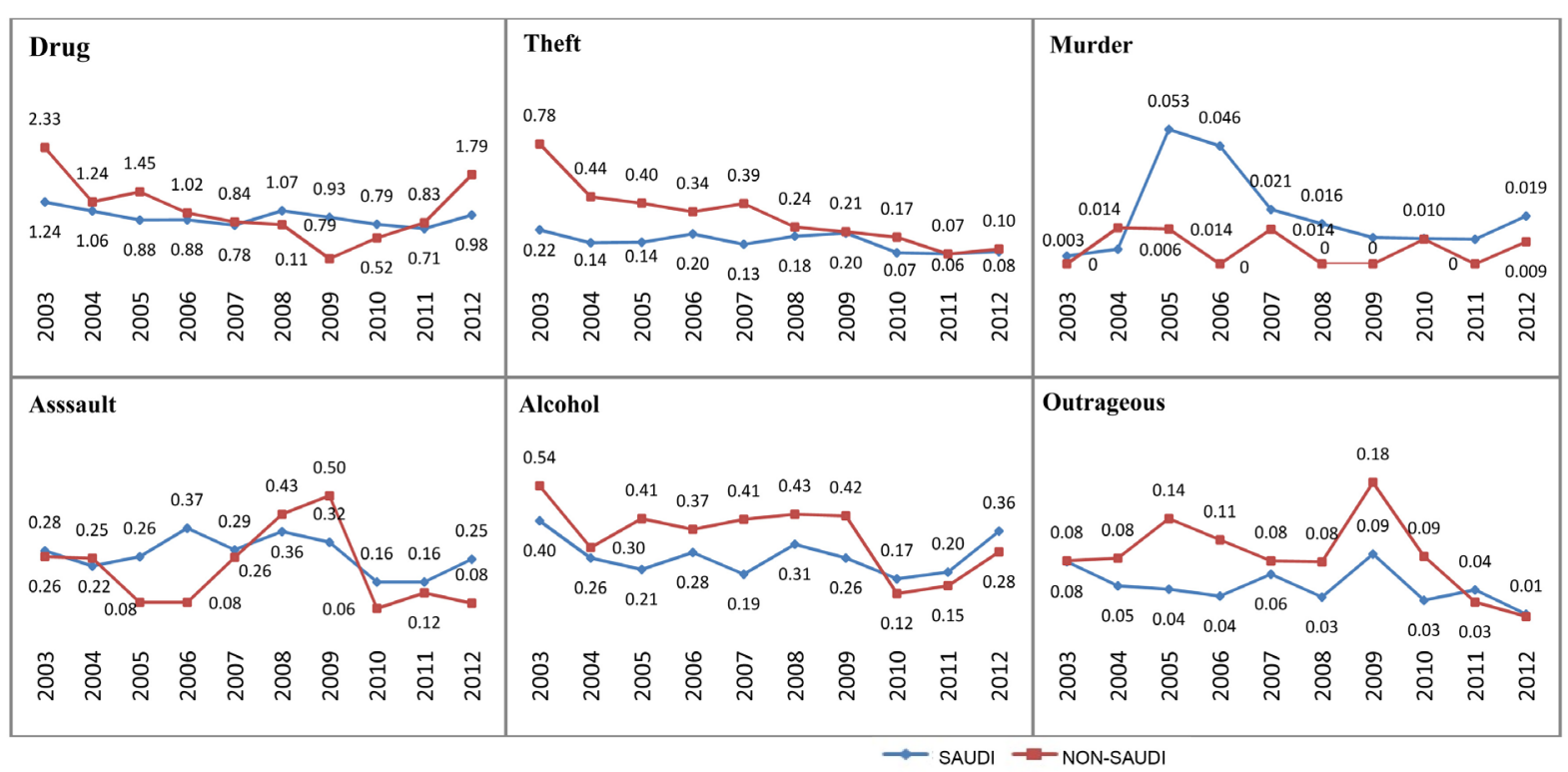

Figure 12. Criminal activities of Najran.

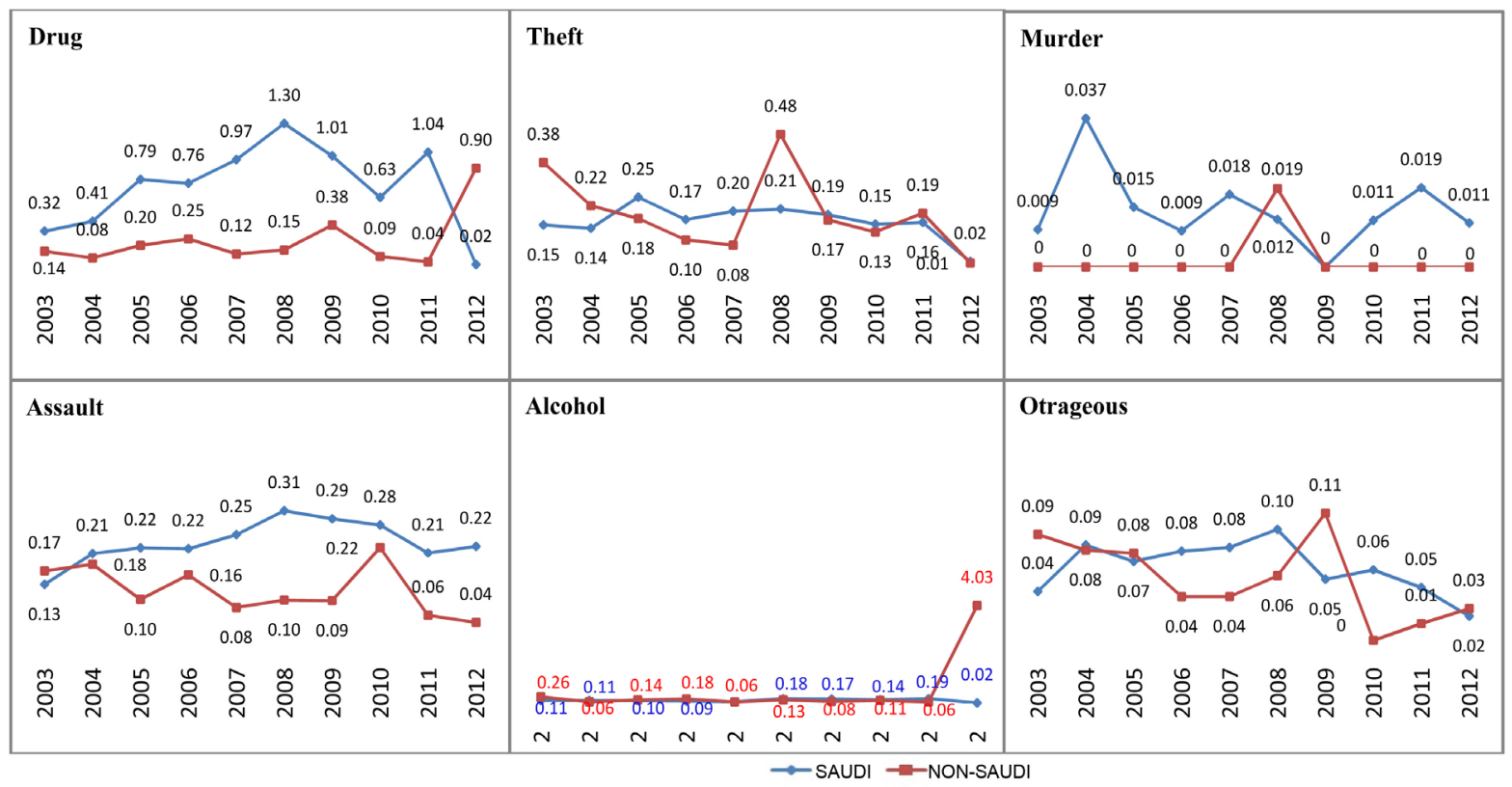

\section{Figure 13. Criminal activities of Jouf.}

2012 in drug activities where the rate doubled that of Saudis. In murder there were no non-Saudi offences in 2005, 2006, 2007 and 2012. However, there were highs in 2004, 2008, 2010 and 2011. Non-Saudi fractionally exceeded Saudi overall for alcohol and for the first five years in outrageous issues, while they were below Saudis in assault with noted increases in 2010 and 2011 (Figure 8).

\subsubsection{Ha'el}

In Ha'el, non-Saudi people generally displayed a lower overall rate in all crimes except in outrageous issues. In drug activity and assault they were generally lower than Saudi. In theft, non-Saudi rates were lower than Saudi until the last two years, recording a far greater number in 2011. In alcohol related crimes they were almost very close to Saudis, except in the first year where they were much higher (Figure 9). 


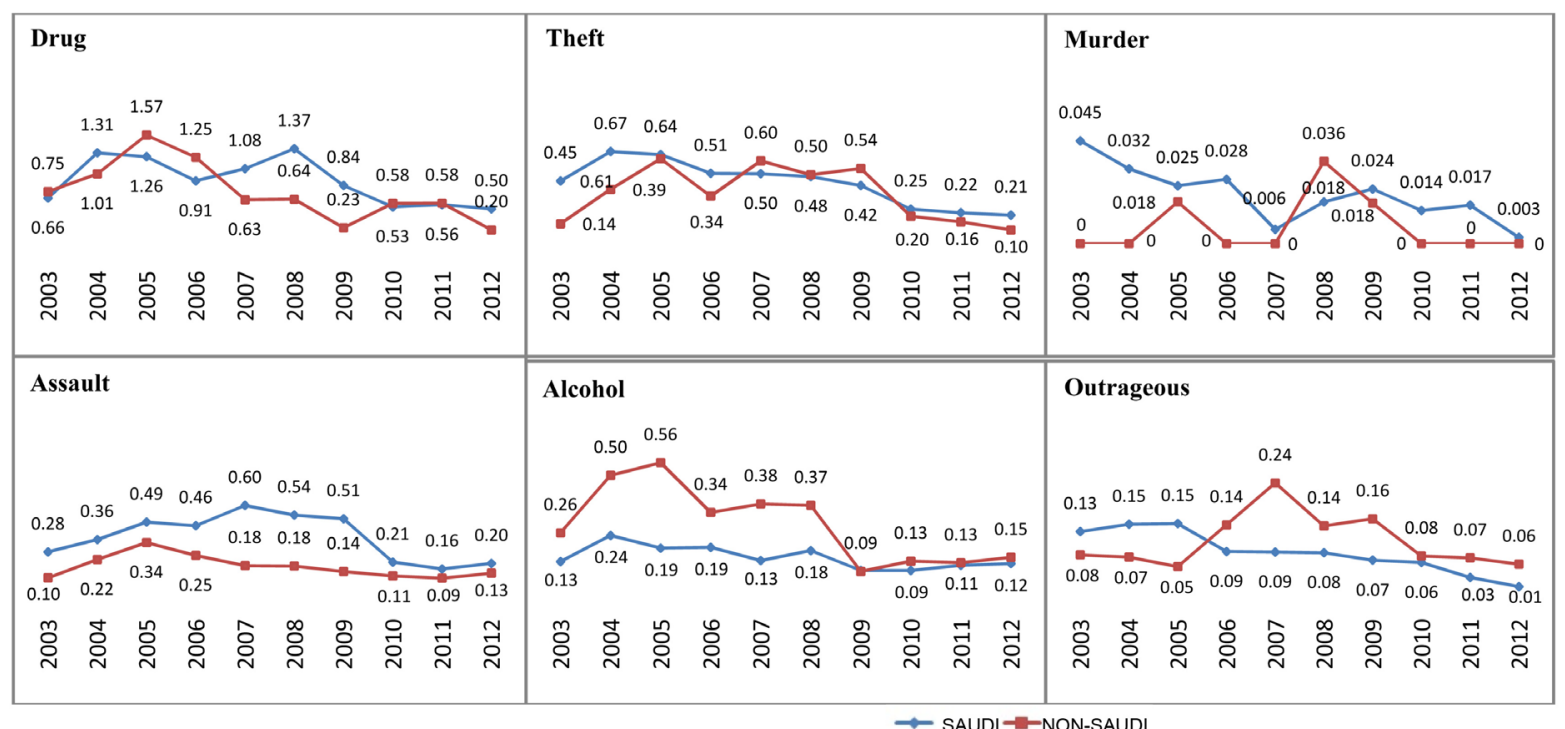

\section{Figure 14. Criminal activities of Baha.}

\subsubsection{Northern Borders}

In Northern Border, non-Saudi crimes exceeded Saudi crimes in outrageous issues, where they were higher throughout the period except in 2007 and 2008. In murder non-Saudis were higher in 2004, 2006 and much higher in 2007, while Saudi rates fluctuated between 0.01 and 0.015 cases per 1000 with a small increase in 2009 to 0.023 cases. In drug activity, non-Saudis were lower than Saudis after 2004, with large variance till the end of the period, except for a notable rise in 2009 which exceeded the rate for Saudis in that year. In theft, non-Saudi rates were lower than Saudis until 2009, where they increased with the Saudi rate decreasing in that year. In the last three years, there was a noted decrease in non-Saudi rates. The variance was large between Saudi and non-Saudi rates for assault, with non-Saudi rates lower after 2003 till the end of the period (Figure 10).

\subsubsection{Jizan}

There were two important signs in Jizan province. The first was that the non-Saudis displayed higher rates, with a very large variance in all criminal issues during the period. Second, the rate of all crimes tended to decrease, especially for non-Saudis. The rates of non-Saudi also showed general signs of decrease in all criminal issues, with far lower variance in theft, murder, alcohol and outrageous issues in 2012, while still greater than the Saudi rate. It decreased to be less than the Saudi rate in the last three years in assault cases, while it remained far higher in drug activity, with a huge variance throughout the period (Figure 11).

\subsubsection{Najran}

In Najran area, non-Saudi rates exceeded Saudis in theft, alcohol and outrageous issues, while the trend of all these issues decreased in the last three years, until it virtually equalled Saudi rate in the last two years in theft cases, and was less than the Saudi rate in the last three years for alcohol and the last two years for outrageous issues. Non-Saudi rates were also high in drug activity during the first five years, then reducing for the years 2008, 2009 and 2010, before rising again to exceed the Saudi rate in the last two years of the period. In murder the rate for non-Saudi fluctuated, but generally was less than the Saudi rate. Non-Saudi rates were close to Saudi in assault for the first two years and higher in 2008 and 2009, while lower in the remaining years (Figure 12).

\subsubsection{Jouf}

In Jouf, the non-Saudi drug activity rate remained low throughout the period until the last year when it became extremely high with a huge variance. The theft rate was high initially, but then decreased until 2007, and then peaked in 2008 with 0.48 cases per 1000 people, while the Saudi rate was only 0.21 cases in that year. After 2008, the non-Saudi rate dropped to close to the Saudi rate in the last four years. There were no murder cases in 
Jouf province by non-Saudi during the ten year period except in 2008, where their cases reached 0.019 per 1000 . In assault non-Saudi rates were less than Saudi, except in the first year where the variance was very small, although there was an increase in 2010, but the range still remained less than the Saudis. Both rates were close for alcohol until 2012, where a dramatic increase was noted in the non-Saudi rate. In the outrageous category, the non-Saudi rate started high in the first year but dropped over the following four years. However it rose again to exceed the Saudi rate in 2009, dropping again to be less than the Saudi rate in 2010 and 2011, but surpassing the Saudi rate in 2012 (Figure 13).

\subsubsection{Baha}

In Baha, the non-Saudi rate was almost as high as the Saudis in both alcohol and outrageous issues, except in the first three years for outrageous. In drug activity, they exceeded the Saudi rate in 2003, 2005, and 2006, though not as greatly in 2010 and 2011. In the remaining years, the rate was lower than the Saudis. There were no visible differences between Saudi and non-Saudi rates in theft cases although non-Saudi recorded a higher rate than Saudi from 2007 to 2009. There were no non-Saudi murder cases in Baha for 7 years. In both 2005 and 2009 , 0.018 cases per 1000 were recorded, while the highest number was recorded in 2008 with 0.036 cases, which exceeded the Saudi rate that year. Non-Saudi rates were lower than Saudis throughout the study period for assault (Figure 14).

\section{Discussion}

It is important to note that there are two major types of immigration to Saudi Arabia. The first is religion-based immigration. Saudi Arabia is the prime destination for 1.6 billion Muslims around the world, and millions of Muslim pilgrims from abroad arrive annually for "Hajj and Umrah”. General statistics for the "Umrah” season in the first quarter of 2015 were 3.8 million pilgrims, and 7.2 million in 2012 for "Hajj” (The Ministry of Hajj Portal, 2015) which makes Saudi Arabia one of the top five tourist destinations worldwide (Central Department for Statistics and Information (CDSI)'s). Saudi Arabian visas for “Hajj and Umrah” for Muslim people are very flexible, quick and easily obtainable, and it is considered a right of every Muslim to enter the country and visit the two holy sites of Makkah and Madinah. Certainly a number of these pilgrims remain in Saudi Arabia illegally every year despite the government's attempts to control this issue [40]. Some of them regularise their situation and most continue to remain undocumented. The second immigration category is worker immigration. Large waves of workers began immigrating to Saudi Arabia in the 1970s after oil was discovered in the country and service projects such as roads, constructions and factories developed, as there was no local competent workforce or predisposition to work at that time [31]-[33]. Saudi Arabia is an attractive place for migrant workers as citizens hire the workers personally and they are not bound by official contracts. Further, Saudi Arabia has a relatively open economy with almost zero tariff rates or non-tariff barriers [32] making it the prime source of remittances for many Arab and Asian countries, since deportations may have significant economic consequences on their fragile economies, and ranked as the second top remittance-sending country in the world in 2012 [41]. The government tends to hire the labour workforce from other Arab countries and Asia, with the majority from southern Asia. There are certainly advantages in hiring Asian workers in Saudi Arabia. First, they are more reliable. Governments in the Asian countries were prepared to send their workers in foreign countries. For example, in the early 1970s Philippine governments marked their workers proficiencies abroad to enter into labour agreements supplying with Middle East countries. Second, Asian workers accept lower wages than others, and do not require the same social support services as the Arabs, who wish to settle and bring their families [31] [42]. In 2013, expatriates numbered 32\% of Saudi Arabia’s population, most of them coming from South Asia. They accounted for $56.5 \%$ of the employed population and $89 \%$ of the private sector workforce. Françoise (2014) found that the irregular migration in Saudi Arabia has become a phenomenon. An amnesty campaign, started in April 2013, allowed 4.7 million foreign workers to regularise their status, while one million illegal immigrants were forced to leave the country in 2013 alone and 547,000 were deported [41]. Most of these large numbers of foreign workers are not highly skilled and had low educational qualifications, as no certificate is required for most work in Saudi Arabia. Workers in skilled and highly-skilled positions numbered between 11 and 12.8 percent of all labour permit holders over the period [41].

Our findings show that there is no positive association between immigration and criminal cases in Saudi Arabia. Figure 1, of the ratio of crimes among both Saudi and non-Saudi, clearly shows that there were only two 
provinces where non-Saudi people have recorded a higher number than Saudi in criminal issues. These were Jizan and Najran, while the ratio was nearly the same in Asir, Baha, Madinah and Jouf. In the other provinces, Saudi people had the highest number of criminal issues. The highest overall levels of criminal activities were in the south, north and Makkah area, where the high numbers of illegal migrants support the basic theory that regions with high levels of immigration experience higher rates of crime [2] [43]. Large numbers of immigrants enter the southern Saudi Arabia, into Jizan and Najran which are adjacent to Yemen, and enter Northern Border in the north, which is adjacent with Iraq. It is known that there have been unacceptable political and social circumstances in these two countries over the last two decades, and most smuggling has occurred in those two border areas of Saudi Arabia. A large number of pilgrims arrive annually in Makkah, thousands of them remaining in Saudi Arabia illegally in search of jobs, and Makkah displays one of the highest rates of non-Saudi crime in theft and outrageous issues. The results also show that the ratio of non-Saudi crimes was five times that of Saudis in Jizan for the whole period, and in the first half of the period for Najran. Further, in terms of murder and aggravated assault results, the non-Saudi crime ratio was lower than in the theft, alcohol and outrageous cases. In Jizan area, the non-Saudi ratio was far higher than Saudi in both murder and aggravated assault during the period, with a variance reaching threefold, particularly in the first six years of the study period. We believe that the most crime activities perpetrated by illegal immigrants, whether in the south or north of the country (Jizan or Northern Borders) supports the criminological theories that suggest that higher levels of immigration lead to higher rates of crime.

Our results show that Jizan is the province most affected by immigrant crimes in all categories, mainly due to the infiltration of tens of thousands of Yemenis and African across the borders of Saudi Arabia and Yemen, seeking employment opportunities which do not exist in their home countries.

Many Saudis consider such large numbers of foreigners in the country a major cause of social and economic problems and argue that these foreign workers deprive young Saudis of training for work and tarnish Saudi Arabia social relations. Until now there has been no effective research which has studied or provided suggestions to resolve these problems in Saudi Arabia.

Our findings confirm that alcohol issue in six provinces and outrageous issue in all provinces except Jouf were much higher among non-Saudis, due to two main reasons. Firstly, alcohol is prohibited in Saudi Arabia by law. However, some foreigners, particularly the illegal sector, produce alcohol in their homes and sell it to make money. Secondly, as already mentioned, foreigners make up a third of the Saudi Arabia population (approximately 10 million), the majority of whom are single which leads to problems in terms of the Saudi culture of extreme gender segregation. As Saudi Arabia is controlled by Islamic law, in Islamic law, any relationship out of marriage is considered a punishable offence for both males and females. Additionally, sexual services, prostitution and strip shows are definitely forbidden by the law. Thus, the Saudi government designates a Religious Authority to supervise this particular issue across the country, and they arrest the transgressors and then send them to the court.

As numbers of foreign workers have increased way beyond the country’s needs, this has imposed a burden on the Saudi government and society in general. Thus the foreign workforce, particularly domestic workers (maids and drivers) needs to be reduced, and it is suggested that the first goal in this area of the Ministry of Labour should be upholding and maintaining the foreign worker rights. Protection from blackmail by their sponsors is essential rather than prosecutions and restrictions. However, recently there has been a proliferation of prosecutions of immigrant criminals, and the Saudi government has established a specialized court for workers in 2014. These specialized courts are geared for judgments between the worker and business owner. In addition, Saudi citizens have contributed to the excess of foreign workers by employing far too many domestic workers, drivers and agricultural workers in the private employment domain. However, we agree with Pinotti [18] that expulsions will reduce the pool of undocumented immigrants who are more at risk of committing crimes.

While accurate data on illegal immigration is generally problematic, we believe that most of the criminal activities, especially in Jizan area, were committed by undocumented immigrants. It should also be noted that there is a significant difference in circumstances between Saudi and non-Saudi accused that may have an effect on numbers extracted from criminal data. Saudi issues such as assault, theft and even murder are sometimes solved by reconciliation or paying compensation to affected parties. Even murder cases may be solved by monetary compensation to the victim's family (blood money). In such cases the crime will not reach the courts. Generally crimes committed by foreigners are not resolved by reconciliation as the workers lack the necessary funds for paying compensation, lack knowledge of Saudi customs or the necessary communication skills. 
Unfortunately, some additional data that may give more explanation to the findings of this study is not available, such as gender, age and income of the offenders. However, it is not within the scope of this paper to unravel demographic characteristics, but future researches in Saudi Arabia may explore these aspects.

\section{Conclusion}

The aim of this research was to explain the effects of immigration on the crime rates in the six most significant categories of Saudi Arabian crime, being drugs activity, theft, murder, assault, alcohol and outrageous issues, during a ten-year period from 2003 to 2012. In addition, it gives insights to help decision making by analysing the historical background of immigrants to Saudi Arabia and demonstrating that immigrants were not more likely to be involved in criminal activity than native Saudis. The link between immigrants and crime, while remaining strong in the public perception for over a century, has by no means obtained universal empirical support. The impact of immigration on crime rates has occupied a significant position in criminological theories and is central to both public and political opinion regarding immigration policy. The existing literature emphasizes that there is a disparity in research outputs about the effects of immigration on crime, and while some scholars argue that immigration causes an increase in crime rates others question the validity of this view, even to the extent of claiming that immigration may lead to a decrease in crime rates in certain national sectors. Our findings support the theories that immigration increases the crime rate, but only in two provinces: Jizan and Najran. Research findings to the contrary clearly do not apply to the Saudi Arabian context, which is unique in two ways. The large number of annual pilgrims to Saudi Arabia and the numbers that attempt to remain illegally after their pilgrimage has a definite impact on crime necessitated by difficult illegal circumstances. Secondly, researchers who found that immigration decreased crime rates applies mainly to other levels of immigration, such as second-generation immigrants, mainly in developed countries with an inveterate immigration system, such as the USA and UK. This study did not overlook the social problems of illegal migrants. In our discussion, we classified Saudi immigration according to two types, being religious and workers. Both types contribute to legal and illegal immigration. Unfortunately, we did not have accurate data for illegal immigration. However, there are some indicators that we mention, such as religious immigration and borders with Yemen, that lead us to discern that there are large numbers of illegal foreigners in Saudi Arabia which is also confirmed by Françoise (2014). Thus our findings show that there is no strong evidence of relationship or positive association between immigration and criminal cases in Saudi Arabia. It is clear in that the high overall crime rates in the south, north and Makkah area, with a high probability of a high rate of illegal immigration, supports the basic theory that regions with high levels of immigration also experience high rates of crime, but this is not true for the whole country. We found that Jizan province suffered greater effects from non-Saudi crime, where the ratio of non-Saudi crime reached more than five times that of Saudi crime. In addition, there is the important factor regarding non-Saudi crime in Saudi Arabia, that there are many foreign workers without supervision outside the formal employment sector engaged in domestic, agricultural and other forms of employment that frequently exploit labour. Thus, we suggest that the Ministry of Labour uphold foreigner worker rights and protect them from exploitation and blackmail of their sponsors. The government should take a firm decision regarding the influential traders who issue thousands of labour visas annually, far in excess of the necessary foreign labour needs of the country, in order to receive illegal monthly income from their visa recipients. A structured system and rules need to be established for citizens requiring domestic and other informal labour to avoid exposing foreigners to exploitation. In the case of existing illegal immigrants, their situation needs to be legalized and regularized, which will reduce the pool of undocumented immigrants at risk of committing crimes and avoid the process of expulsion after crimes have been committed. An additional data that may give more explanation to the findings of this study is not available, such as gender, age and income of the offenders. However, it is not within the scope of this paper to unravel demographic characteristics, but this study will be of particular interest to those who aim to investigate this aspect and the relationship between crime and immigration, especially in Saudi Arabia.

\section{References}

[1] Li, X. and Juhola, M. (2014) Country Crime Analysis Using the Self-Organizing Map, with Special Regard to Demographic Factors. AI \& Society, 29, 53-68. http://dx.doi.org/10.1007/s00146-013-0441-7

[2] Wadsworth, T. (2010) Is Immigration Responsible for the Crime Drop? An Assessment of the Influence of Immigration on Changes in Violent Crime between 1990 and 2000. Social Science Quarterly, 91, 531-553. 
http://dx.doi.org/10.1111/j.1540-6237.2010.00706.x

[3] Butcher, K.F. and Piehl, A.M. (1998) Cross-City Evidence on the Relationship between Immigration and Crime. Journal of Policy Analysis and Management, 17, 457-493.

http://dx.doi.org/10.1002/(SICI)1520-6688(199822)17:3<457::AID-PAM4>3.0.CO;2-F

[4] Newton, A. and Felson, M. (2015) Editorial: Crime Patterns in Time and Space: The Dynamics of Crime Opportunities in Urban Areas. Crime Science, 4, 1-5. http://dx.doi.org/10.1186/s40163-015-0025-6

[5] Farrell, G. (2013) Five Tests for a Theory of the Crime Drop. Crime Science, 2, 1-8. http://dx.doi.org/10.1186/2193-7680-2-5

[6] Martucci, P. (2015) Migrations and Crime in the History of Criminology. The Case of the Immigration Restriction League in the United States. Italian Journal of Criminology, 8, 112-119.

[7] Abbott, E. (1931) The Problem of Crime and the Foreign Born in National Commission on Law Observance and Enforcement. Report on Crime and the Foreign Born, United States Government Printing Office, Washington DC.

[8] Van Vechten, C.C. (1941) The Criminality of the Foreign Born. Journal of Criminal Law and Criminology, 139-147.

[9] Mariani, F. (2010) Migration and Crime. IRES, Université Catholique de Louvain, Paris School of Economics, IZA, Bonn.

[10] Reid, L.W., et al. (2005) The Immigration-Crime Relationship: Evidence across US Metropolitan Areas. Social Science Research, 34, 757-780. http://dx.doi.org/10.1016/j.ssresearch.2005.01.001

[11] Kinman, J.L. and Lee, E.S. (1966) Migration and Crime. International Migration Digest, 7-14. http://dx.doi.org/10.2307/3002915

[12] Salvatore, R.D. and Aguirre, C. (2010) The Birth of the Penitentiary in Latin America: Essays on Criminology, Prison Reform, and Social Control, 1830-1940. University of Texas Press.

[13] Anderson, N. (1998) On Hobos and Homelessness. University of Chicago Press.

[14] Park, R.E. (1928) Human Migration and the Marginal Man. American Journal of Sociology, 881-893. http://dx.doi.org/10.1086/214592

[15] Stonequist, E.V. (1937) The Marginal Man: A Study in Personality and Culture Conflict. Russell \& Russell, New York.

[16] Butcher, K.F. and Piehl, A.M. (1998) Recent Immigrants: Unexpected Implications for Crime and Incarceration. Industrial \& Labor Relations Review, 51, 654-679. http://dx.doi.org/10.1177/001979399805100406

[17] Killias, M. (1997) Immigrants, Crime, and Criminal Justice in Switzerland. Crime and Justice, 375-405. http://dx.doi.org/10.1086/449254

[18] Pinotti, P. (2015) Immigration Enforcement and Crime. Baffi Center Research Paper, 2015-166.

[19] Yeager, M.G. (1997) Immigrants and Criminality: A Cross-National Review. Criminal Justice Abstracts.

[20] Bell, B., Fasani, F. and Machin, S. (2013) Crime and Immigration: Evidence from Large Immigrant Waves. Review of Economics and Statistics, 21, 1278-1290. http://dx.doi.org/10.1162/REST_a_00337

[21] Jaitman, L. and Machin, S. (2013) Crime and Immigration: New Evidence from England and Wales. IZA Journal of Migration, 2, 19. http://dx.doi.org/10.1186/2193-9039-2-19

[22] Papadopoulos, G. (2014) Immigration Status and Property Crime: An Application of Estimators for Underreported Outcomes. IZA Journal of Migration, 3, 12. http://dx.doi.org/10.1186/2193-9039-3-12

[23] Webb, R.T., et al. (2015) National Cohort Study of Suicidality and Violent Criminality among Danish Immigrants. PLoS ONE, 10, e0131915. http://dx.doi.org/10.1371/journal.pone.0131915

[24] Beckley, A.L. (2015) Age at Immigration and Crime in Stockholm Using Sibling Comparisons. Social Science Research, 53, 239-251. http://dx.doi.org/10.1016/j.ssresearch.2015.06.006

[25] Hoefer, M., Rytina, N. and Baker, B.C. (2011) Estimates of the Unauthorized Immigrant Population Residing in the United States: January 2010. Population Estimates, Office of Immigration Statistics, Department of Homeland Security, 4.

[26] Morehouse, C. and Blomfield, M. (2011) Irregular Migration in Europe. Migration Policy Institute, Washington DC.

[27] Baker, S.R. (2014) Effects of Immigrant Legalization on Crime: The 1986 Immigration Reform and Control Act. Stanford Law and Economics Olin Working Paper No. 412.

[28] Freedman, M., Owens, E. and Bohn, S. (2013) Immigration, Employment Opportunities, and Criminal Behavior. Unpublished Manuscript, Cornell University, Ithaca.

[29] Pinotti, P. (2014) Clicking on Heaven's Door: The Effect of Immigrant Legalization on Crime. Baffi Center Research Paper No. 2014-154. http://dx.doi.org/10.2139/ssrn.2426502 
[30] Mastrobuoni, G. and Pinotti, P. (2014) Legal Status and the Criminal Activity of Immigrants. Upjohn Institute Working Paper No. 14-212. http://dx.doi.org/10.2139/ssrn.2438682

[31] Abella, M.I. (1995) Asian Migrant and Contract Workers in the Middle East. The Cambridge Survey of World Migration. Cambridge University Press, Cambridge, 418-423.

[32] Nassar, H. and Ghoneim, A. (2002) Trade and Migration, Are They Complements or Substitutes: A Review of Four MENA Countries. Economic Research Forum for the Arab Countries, Iran \& Turkey.

[33] Fergany, N. (2001) Aspects of Labor Migration and Unemployment in the Arab Region. Almishkat Center for Research, Cairo, 3.

[34] Kapiszewski, A. (2006) Arab versus Asian Migrant Workers in the GCC Countries. United Nations Expert Group Meeting on International Migration and Development in the Arab Region, Beirut, 15-17 May 2006.

[35] Mohammed, A.-O. (2005) The Role of Foreign Workers in the Promotion of Drugs, in Naif Arab University for Security Sciences.

[36] Ghadah, A.-T. (2009) The Crime of Maids in Saudi Society. The Arabic Journal of Security Studies and Training.

[37] Alrashed, M. and Alunizan, A. (2012) The Kingdom of Saudi Arabia Facts \& Numbers. Saudi Geological Survey, Saudi Arabia, 116.

[38] Ali, B.-E.-D. (1985) Islamic Law and Crime: The Case of Saudi Arabia. International Journal of Comparative and Applied Criminal Justice, 9, 45-57. http://dx.doi.org/10.1080/01924036.1985.9688820

[39] Vogel, F.E. (2000) Islamic Law and the Legal System of Saudí: Studies of Saudi Arabia. Vol. 8, Brill.

[40] Algahtany, M., Kumar, L. and Khormi, H.M. (2014) Spatio-Temporal Changes on Crime Patterns in Saudi Arabia from 2003-2012. Journal of Law and Social Sciences, 4, 11-19. http://dx.doi.org/10.5176/2382-5642_fscr14.27

[41] De Bel-Air, F. (2014) Demography, Migration and Labour Market in Saudi Arabia. 1: Gulf Research Center, Publication No. 1.

[42] Balcer, J. (2014) Controlling Influence: The Development and Function of Labor Law in Saudi Arabia. Electronic Theses, Treatises and Dissertations, Florida State University, Tallahassee, Paper 9134.

[43] Shaw, C.R. and McKay, H.D. (1942) Juvenile Delinquency and Urban Areas: A Study of Rates of Delinquents in Relation to Differential Characteristics of Local Communities in American Cities. The University of Chicago Press, Chicago. 